University of Nebraska - Lincoln

DigitalCommons@University of Nebraska - Lincoln

\title{
Patterns of Plant Species Diversity in Remnant and Restored Tallgrass Prairies
}

\author{
H. Wayne Polley \\ United States Department of Agriculture, wayne.polley@ars.usda.gov \\ Justin D. Derner \\ USDA-ARS, Justin.Derner@ars.usda.gov \\ Brian J. Wilsey \\ lowa State University
}

Follow this and additional works at: https://digitalcommons.unl.edu/usdaarsfacpub

Part of the Agricultural Science Commons

Polley, H. Wayne; Derner, Justin D.; and Wilsey, Brian J., "Patterns of Plant Species Diversity in Remnant and Restored Tallgrass Prairies" (2005). Publications from USDA-ARS / UNL Faculty. 451.

https://digitalcommons.unl.edu/usdaarsfacpub/451

This Article is brought to you for free and open access by the U.S. Department of Agriculture: Agricultural Research Service, Lincoln, Nebraska at DigitalCommons@University of Nebraska - Lincoln. It has been accepted for inclusion in Publications from USDA-ARS / UNL Faculty by an authorized administrator of DigitalCommons@University of Nebraska - Lincoln. 


\title{
Patterns of Plant Species Diversity in Remnant and Restored Tallgrass Prairies
}

\author{
H. Wayne Polley, ${ }^{1,2}$ Justin D. Derner, ${ }^{3}$ and Brian J. Wilsey ${ }^{4}$
}

\begin{abstract}
To restore diversity of native vegetation, we must understand factors responsible for diversity in targeted communities. These factors operate at different spatial scales and may affect the number and relative abundances of species differently. We measured diversity of plant species and functional groups of species in replicated plots within paired restored and remnant (relic) tallgrass prairies at three locations in central Texas, U.S.A. To determine the contributions of species abundances and of spatial patterns of diversity to differences between prairie types, we separated diversity into richness and evenness (relative biomass) and into within-plot $(\alpha)$, among-plot $(\beta)$, and prairie $(\gamma)$ components. Species diversity was greater in remnant than in restored prairies at all spatial scales. At the $\gamma$ scale, both species richness and species evenness were greater in remnants because of greater spatial variation in species composition. At the $\alpha$ scale, remnants were more diverse because of greater richness alone. Mean $\alpha$ richness correlated positively with the size of the species
\end{abstract}

pool in restored prairies only, implying that in remnants, $\alpha$ richness was influenced more by colonization dynamics than by the number of species available for colonization. Plots in remnant prairies contained more functional groups and fewer species per group than did plots in restored prairies, suggesting that resource partitioning was greater in relic prairies. Our results are consistent with the interpretation that local ecological processes, like resource partitioning and limitations on seed dispersal, contribute to the greater diversity of remnant than restored prairies in central Texas. Restoration practices that limit abundances of competitive dominants, increase the number of species in seed mixtures, and increase the proximity of plants of different functional groups thus may be required to better simulate the plant diversity of tallgrass prairies.

Key words: colonization limitation, functional groups, niche partitioning, prairie restoration, species diversity, species evenness, species richness, tallgrass prairie.

\section{Introduction}

Greater than $90 \%$ of the area once occupied by the floristically diverse tallgrass prairie in North America has been modified for agriculture (Samson \& Knopf 1994), resulting in a loss of biodiversity and ecosystem services. Efforts to restore tallgrass prairie plants now are widespread, but goals of prairie restoration vary. One aim is to reestablish functional properties of native communities, like erosion control or nutrient cycling, for which few species may be required (Baer et al. 2002). The goal of recreating the patterns of plant species richness and abundances found in remnant prairies has proven more difficult to achieve (Howe 1994) partly because mechanisms responsible for diversity in targeted communities are poorly understood. There are least two general reasons. First, diversity is controlled by interactive processes that operate at different spatial and temporal scales (Huston 1999). Second, the

\footnotetext{
${ }^{1}$ Grassland, Soil and Water Research Laboratory, U.S. Department of Agriculture, Agricultural Research Service, Temple, TX 76502, U.S.A.

2 Address correspondence to H. W. Polley, email wpolley@spa.ars.usda.gov

${ }^{3}$ High Plains Grasslands Research Station, U.S. Department of Agriculture,

Agricultural Research Service, Cheyenne, WY 82009, U.S.A.

${ }^{4}$ Department of Botany, Iowa State University, Ames, IA 50012, U.S.A.

two components of diversity, species richness (number of species per unit area) and species evenness (equitability of species abundances) may respond differently to ecological factors or across spatial scales (Wilson et al. 1999; Stirling \& Wilsey 2001).

Discerning the primary scales at which diversity is regulated may be an important step in learning to restore species diversity in plant communities (Huston 1999; Loreau 2000). If species richness is regulated primarily at the scale of interacting plants (local scale), for example, methods that reduce the intensity of local competition may be required to restore richness. If, on the other hand, species number is regulated primarily by processes at the amongplot scale, methods that increase spatial heterogeneity in disturbance regimes or in the availability of resources may be required to restore richness.

Diversity at even a single spatial scale may depend on processes that operate at different scales. Richness of potentially interacting species (local richness) traditionally has been attributed to processes that ameliorate effects of competition, for example. These processes include spatial or temporal differences in resource use by plants (niche partitioning), environmental fluctuations, dispersal limitations on competitive dominants, and disturbances and herbivores that inflict greatest damage on dominant species 
(reviewed by Chesson 2000). Local richness, however, also depends on the size of the regional pool of species (Taylor et al. 1990; Eriksson 1993; Gough et al. 1994; Zobel 1997).

A frequent goal of prairie restoration is to re-create the patterns of plant species richness found in remnant prairies. Consequently, restorations are monitored primarily for the number of native species that are present. Less attention has been given to measuring species abundances (evenness). Low levels of evenness, however, may indirectly reduce species richness by increasing the rate of local extinctions (Wilsey \& Polley 2004). In highly uneven assemblages, many species are rare, and rare species of plants are especially prone to local extinction (Duncan \& Young 2000). To increase or maintain richness over the long-term thus may require a better understanding of the processes that promote equitability in species abundances.

We measured diversity (Simpson's index) of plant species and functional groups of species (defined based on growth form and phenology) in replicated plots (total of 72) located in three restored and three remnant (relic) tallgrass prairies in central Texas. We then separated diversity into richness and evenness (relative biomass) and into spatial (within plot, among plot, total or prairie; Lande 1996; Veech et al. 2002) components to test the prediction that richness and evenness were greater in remnant than in restored prairies at both the within-plot and the prairie scales. Few studies have documented patterns of both species richness and abundances in restorations (e.g., Kindscher \& Tieszen 1998). Fewer still have investigated how diversity changes across spatial scales.

We also analyzed data for evidence that local ecological processes, like niche partitioning and limitations on seed dispersal, might explain differences in species diversity between prairie types. To our knowledge, the analyses used here have not been applied in the context of restoration. First, we determined relationships between the mean richness of small plots and the size of the species pool for each prairie type to test the prediction that richness at the local scale of interacting species is more strongly correlated with the size of the available species pool in restored than in remnant prairies. Second, we compared the observed distribution of species among functional groups in each prairie type with expectations generated by ran- domly sampling from the species pool to test the prediction that functional diversity among co-occurring species was greater than expected by chance in remnant but not in restored prairies.

\section{Methods}

\section{Site Characteristics and Sampling}

We measured plant species diversity in pairs of remnant and restored tallgrass prairies at each of three sites in the Blackland Prairie region of central Texas, U.S.A. The Blackland Prairie is located near the southern extreme of the tallgrass prairie that once extended northward through the central United States to North Dakota. Along a 310-km gradient from northeast to southwest, sites are located near Farmersville (lat $33^{\circ} 16^{\prime} \mathrm{N}$, long $96^{\circ} 36^{\prime} \mathrm{W}$ ), Riesel (lat $31^{\circ} 28^{\prime} \mathrm{N}$, long $96^{\circ} 55^{\prime} \mathrm{W}$ ), and Temple (lat $31^{\circ} 05^{\prime} \mathrm{N}$, long $\left.97^{\circ} 20^{\prime} \mathrm{W}\right)$. Soils at all study sites are vertisols with a clay content of greater than $50 \%$. Annual precipitation varies between $1,060 \mathrm{~mm}$ at the northernmost site (Farmersville) and $879 \mathrm{~mm}$ (89-year average) at the southernmost site (Temple), with peaks in spring and autumn.

At each site, tallgrass prairie was restored by applying "seed hay" collected from the remnant prairie to a previously cultivated field. Restored prairies are located within $10 \mathrm{~km}$ of remnant prairies at each site and were seeded 9 (Riesel), 10 (Farmersville), and 20 (Temple) years prior to sampling. The two prairies at each site were managed similarly (hayed or burned). None of the six prairies was grazed by domestic livestock. Prairies varied in size from 0.5 to 21 ha (Table 1 ). Most of the land surrounding prairies is cultivated.

In June of 2001, we clipped aboveground biomass to $2 \mathrm{~cm}$ height in each of 12 randomly located plots $(0.71 \times$ $0.71 \mathrm{~m} ; 0.5 \mathrm{~m}^{2}$ ) in each of the six prairies (total of 72). Sampling was timed to correspond with the period of peak biomass for most species in these prairies. Live (green) tissue removed from each plot was separated by species, dried to constant mass at $60^{\circ} \mathrm{C}$, and then weighed.

\section{Diversity}

For each of the six prairies, we calculated diversity and its components (richness and evenness based on relative

Table 1. Properties of remnant and restored prairies at each of the three sites in the Blackland (tallgrass) Prairie region of central Texas, U.S.A.

\begin{tabular}{|c|c|c|c|c|c|c|}
\hline & Remnant & Restored & Remnant & Restored & Remnant & Restored \\
\hline Live biomass $\left(\mathrm{g} / \mathrm{m}^{2}\right)$ & 290.1 & 180.8 & 217.4 & 148.7 & 158.0 & 156.4 \\
\hline Species diversity & 12.7 & 2.3 & 5.6 & 3.5 & 9.0 & 2.7 \\
\hline Species richness & 43 & 30 & 41 & 34 & 42 & 24 \\
\hline Species evenness & 0.30 & 0.08 & 0.14 & 0.10 & 0.21 & 0.11 \\
\hline
\end{tabular}

Biomass and indexes of species composition and diversity ( $\gamma$ or prairie scale) were derived from harvests of twelve 0.5 - $\mathrm{m}^{2}$ plots from each of the six prairies. 
biomass) at each of three spatial scales ( $\alpha$, within plot; $\beta$, among plot; $\gamma$, total). Species diversity was calculated using Simpson's reciprocal index $(D)$, where $D=1 / \sum_{i=1}^{S} p_{i}^{2}$ and $p_{i}$ is the proportion of biomass contributed by species $i$ to total biomass and $S$ is the total number of species present (species richness). Species evenness $(E)$, the equitability with which abundances are distributed among species, was calculated as the ratio of $D$ to $S$. Unlike the measure of $E$ that is derived from the frequently used Shannon-Weiner index of diversity, the $E$ calculated from Simpson's $D$ is mathematically independent of species $S$ (Smith \& Wilson 1996). We also calculated evenness of biomass distribution among the four species that contributed the bulk of biomass $(>80 \%)$ in each plot.

As a measure of functional diversity, we calculated diversity indexes using 10 functional groups of species (defined based on phenology and growth form). Functional groups were defined using a three-tiered hierarchical structure of traits. Species were classified first into growth form, as grasses, shrubs, or forbs (nongrass, herbaceous species). For each growth form, species then were classified as either early-season or late-season species, depending on whether plants flowered and completed most growth before or after the beginning of June of each year. Finally, early- and late-season species within the grass and forb growth forms were classified either as annuals or perennials. All shrubs were perennials.

Species and functional group data from the 12 plots sampled per prairie were combined to calculate total or gamma $(\gamma)$ diversity, richness, and evenness. Within-plot or alpha $(\alpha)$ diversity and among-plot or beta $(\beta)$ diversity then were calculated for each plot $j$, where $\beta_{j}=\gamma-\alpha_{j}$ (Lande 1996; Veech et al. 2002). Here, $\beta$ diversity is the average amount of diversity not found in a single plot (Veech et al. 2002) and thus is defined relative to our measure of $\alpha$ diversity. Diversity, richness, and evenness at the $\alpha$ and $\beta$ scales ( $n=12$ measurements per prairie) were analyzed using a two-factor analysis of variance (ANOVA), with site (2 degrees of freedom $[d f]$ ) and prairie type (remnant, restored; $1 d f$ ) as main factors and $66 d f$ in the error term. Significant differences among three or more means were assessed with Student-Newman-Keuls multiple range test. Paired $t$ tests were used to determine differences among prairie types in $\gamma$ diversity ( $n=3$ pairs). Relationships between diversity indexes and the area of prairies were examined using linear regression.

\section{Relationships Between Richness at the Plot and Prairie Scales}

A linear relationship between plot-scale $S$ and the size of the species pool usually is taken as evidence that the local community is not saturated with species (Cornell \& Lawton 1992). Tests of this relationship are biased, however, if both $S$ and pool size are calculated from the same set of data (Srivastava 1999). To provide for greater independence between variables, we partitioned data collected from $0.5-\mathrm{m}^{2}$ plots in each prairie into subsets from which plot-scale $S$ and size of the species pool were estimated (Collins et al. 2002). For each prairie, we estimated mean $S$ of plots as the average $S$ of 3 randomly selected plots of the 12 plots sampled. Size of the actual species pool was estimated from the remaining nine plots from each prairie. The procedure was repeated 1,000 times to ensure that estimates were unbiased. The 1,000 estimates of plot-scale $S$ and of pool size for each prairie were averaged, and a linear regression was used to determine the strength of the relationship between these variables for each prairie type.

\section{Distribution of Species among Functional Groups}

Ecological function should differ more predictably between functional groups than between species. A demonstration that potentially interacting species are not randomly distributed among functional groups is evidence for a role of ecological processes in structuring the composition of local communities. To determine whether the number of species per functional group in $0.5-\mathrm{m}^{2}$ plots differed significantly from expectation, we performed two Monte Carlo simulations. Our null hypothesis in each was that the observed distribution of species among functional groups did not differ from the distribution derived by randomly sampling from the pool of available species. We first assigned species randomly and with replacement to each of the 12 plots in each prairie from the species pool of the prairie. For each prairie, the species pool was defined as the total number of species encountered across all plots sampled. The number of species assigned to plots during simulations equaled the number of species that was observed in each plot. This randomization method permits any species to be either abundant or rare. To produce random communities that preserved sampled abundances of species, we performed a second randomization in which species occurred in the same total number of plots per prairie as in observations and in which the number of species per plot remained as observed. Each randomization procedure was repeated 100 times for each remnant and restored prairie. Following each randomization, power functions were fit to relationships between the number of functional groups and number of species per plot for each prairie type (remnant, restored). For each prairie type, we compared the scaling exponents from the regressions developed with observed data to the $95 \%$ confidence intervals of exponents derived from randomizations.

\section{Results}

\section{Species Composition and Total Biomass}

Remnant and restored prairies at both Riesel and Temple were dominated by the $\mathrm{C}_{4}$ grass Little bluestem (Schizachyrium scoparium (Michx.) Nash; 22-58\% of biomass). The subdominant species in restored prairies at these sites was the $\mathrm{C}_{4}$ grass Indian grass (Sorghastrum nutans (L.) 
Nash). In contrast, subdominant species in remnant prairies were the forbs Basket-flower (Centaurea americana Nutt.) and Prairie-plantain (Arnoglossum [formerly Cacalia] plantagineum Raf.). The $\mathrm{C}_{4}$ grasses Eastern gamma grass (Tripsacum dactyloides (L.) L.) and S. nutans dominated remnant and restored prairies, respectively, at the Farmersville site. Schizachyrium scoparium was the subdominant species in both Farmersville prairies. Live biomass ranged between $148.7 \mathrm{~g} / \mathrm{m}^{2}$ in the restored prairie at Riesel and $290.1 \mathrm{~g} / \mathrm{m}^{2}$ in the remnant prairie at Farmersville (Table 1).

\section{Species and Functional Group Diversity}

Species diversity was greater in remnant than in restored prairies at the within-plot $(\alpha)$ and prairie $(\gamma)$ scales (Fig. 1). At the $\gamma$ scale, diversity was greater on average by a factor of 3 in remnants. Diversity did not differ significantly among sites $(p>0.73$; Table 1$)$. Differences in among-plot $(\beta)$ diversity between prairie types depended on site $(p<0.0001$, for the site $\times$ prairie type interaction in ANOVA). The $\beta$ diversity was greater in remnant than in restored prairies at Farmersville $(\bar{X}=7.9$ and 0.3$)$ and Temple $(\bar{X}=5.1$ and $0.2, p<0.05$ from multiple range test) but did not differ between prairies at Riesel $(\bar{X}=1.4$ and $0.7, n=12$ per prairie).

Linear regression analyses indicated that there was no relationship between species richness $(S)$ and prairie area at either the $\gamma$ or the $\beta$ scales for restored $(p>0.18, n=3)$ or remnant grasslands $(p>0.22, n=3)$. Indeed, $\gamma$ richness varied by only two species among remnants that differed in size by a factor of 13 (Table 1). Regressions were not improved by logarithmically transforming area (not shown). Because plots were randomly located in each prairie, the distance between plots was greater on average in large than small prairies (not shown). Greater separation in space could contribute to the sampling of greater spatial heterogeneity and to greater variation among plots in $S$ and species composition. For a given prairie type, however, among-plot variation in $S$ ( $\beta$ richness) was not a simple function of area.

Species richness was greater in remnant than in restored prairies at the $\alpha, \beta$, and $\gamma$ scales (Fig. 1). At the $\gamma$ scale, restored prairies contained between $57 \%$ (Temple) and $83 \%$ (Riesel) of the number of species encountered in remnants (Table 1). Exotic species, defined as species that originated outside the continental United States, were few in both remnant and restored prairies. Exotic species comprised less than $12 \%$ of species richness in prairies and contributed an even smaller percentage of live biomass. Differences between remnant and restored prairies in $\beta$ richness depended on site $(p<0.0001$, for the site $\times$ prairie type interaction in ANOVA). Among-plot or $\beta$ richness was greater in remnant than in restored prairies at Farmersville $(\bar{X}=29.5$ and 22.0$)$ and Temple $(\bar{X}=31.9$ and 17.7, $p<0.05$ from multiple range test) but did not differ between prairie types at Riesel ( $n=12$ per prairie).

The $S$ of small plots differed among sites $(p=0.0001$ from ANOVA). Averaged across the two prairie types,
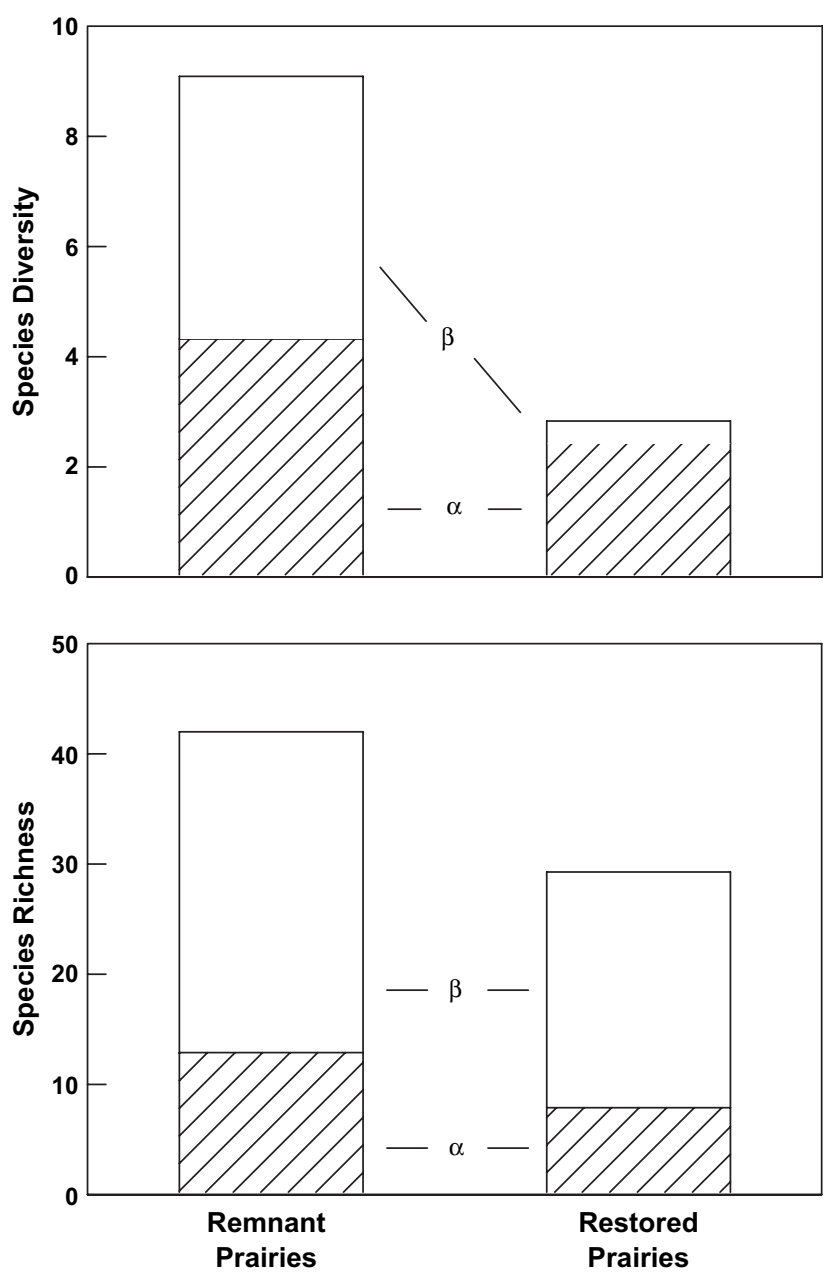

Figure 1. Mean values of plant species diversity (upper panel, Simpson's index) and species richness (lower panel) in remnant and restored tallgrass prairies in the Blackland Prairie region of central Texas, U.S.A. Species diversity and richness were measured in twelve $0.5-\mathrm{m}^{2}$ plots in each prairie type at each of the three locations. Total- or $\gamma$ diversity and richness were additively partitioned into within-plot $(\alpha)$ and between-plot $(\beta)$ components. Remnant and restored prairies differed in $\alpha$ ( $n=36$ per prairie type) and $\gamma(n=3$ per prairie type) components of diversity $(p<0.0001$ and 0.04 , respectively) and richness ( $p<0.0001$ and 0.01 , respectively). Differences in $\beta$ diversity and richness between remnant and restored prairie depended on location $(p<0.0001)$.

the number of species in $0.5-\mathrm{m}^{2}$ plots ( $\alpha$ richness) was least at the Temple site ( 8.2 species, $p<0.05$ from multiple range test) and did not differ significantly between the Farmersville and Riesel sites (10.8 and 12.3 species, respectively; $n=12$ per prairie).

Species evenness at the prairie scale $(\gamma)$ was greater on average in remnant $(0.22)$ than in restored $(0.10)$ prairies ( $t$ test, $p=0.07$; Table 1$)$. Evenness at the plot scale $(\alpha)$ did not differ between prairie types, but evenness calculated for the four most abundant species per plot (dominants) was significantly greater in remnants (Table 2). These dominant species contributed a mean of $82 \%$ 
Table 2. Mean values of indexes related to plant diversity at the within-plot $\left(0.5 \mathrm{~m}^{2}\right)$ or $\alpha$ scale in remnant and restored prairies across three sites in the Blackland (tallgrass) Prairie region of central Texas, U.S.A. $(n=36$ per prairie type).

\begin{tabular}{|c|c|c|c|}
\hline & $\begin{array}{l}\text { Remnant } \\
\text { Prairies }\end{array}$ & $\begin{array}{l}\text { Restored } \\
\text { Prairies }\end{array}$ & $\begin{array}{c}p \\
\text { Value }\end{array}$ \\
\hline Species evenness & 0.35 & 0.34 & 0.62 \\
\hline $\begin{array}{l}\text { Evenness among four } \\
\text { dominant species per plot }\end{array}$ & 0.74 & 0.54 & $<0.0001$ \\
\hline $\begin{array}{l}\text { Number of functional groups } \\
\text { among four dominant } \\
\text { species per plot }\end{array}$ & 3.0 & 2.4 & 0.0002 \\
\hline Functional group richness & 5.64 & 3.58 & $<0.0001$ \\
\hline Functional group evenness & 0.51 & 0.44 & 0.03 \\
\hline
\end{tabular}

Data were analyzed with a two-factor ANOVA with site and prairie type as main factors.

(native prairies) and $95 \%$ (restored prairies) of aboveground live biomass to plots.

Plot-scale richness and evenness of functional groups both were greater in remnant than in restored prairies (Table 2). As indicated by ANOVA, the number of functional groups represented among the four dominant species per plot also was greater in remnants.

\section{Relationship Between Richness at the Plot and Prairie Scales}

We randomly partitioned data from small plots into subsets from which $S$ of plots and size of the species pool were estimated. Mean $S$ of $0.5-\mathrm{m}^{2}$ plots correlated positively with the species pool in restored prairies $(r=0.99945, p=$ 0.02 from linear regression), but there was no relationship between plot-scale $S$ and size of the species pool in remnant prairies ( $p=0.85$; Fig. 2 ).

\section{Distribution of Species among Functional Groups}

To examine relationships between the number of species $(S)$ and number of functional groups of species $(F)$ present in $0.5-\mathrm{m}^{2}$ plots in remnant and restored prairies, data from each prairie type were fit with power functions, where $F=S^{x}$. Exponents of power functions were smaller than 1 for both prairie types (Fig. 3), meaning that increases in $\alpha$ richness were accompanied by a uniform, but proportionally smaller, increase in the number of functional groups (functional diversity). As a consequence, the number of species per functional group increased as species richness increased. The exponent of the species functional group relationship was significantly $(p<0.05)$ greater across remnants than restored prairies, evidence that species in small plots were functionally more diverse, on average, in remnants.

To assess the possible role of plant interactions in plotscale functional relationships, we compared the composition of the seventy-two $0.5-\mathrm{m}^{2}$ plots sampled to the composition generated by randomly sampling the larger species pool in which plots were embedded. Randomizations yielded

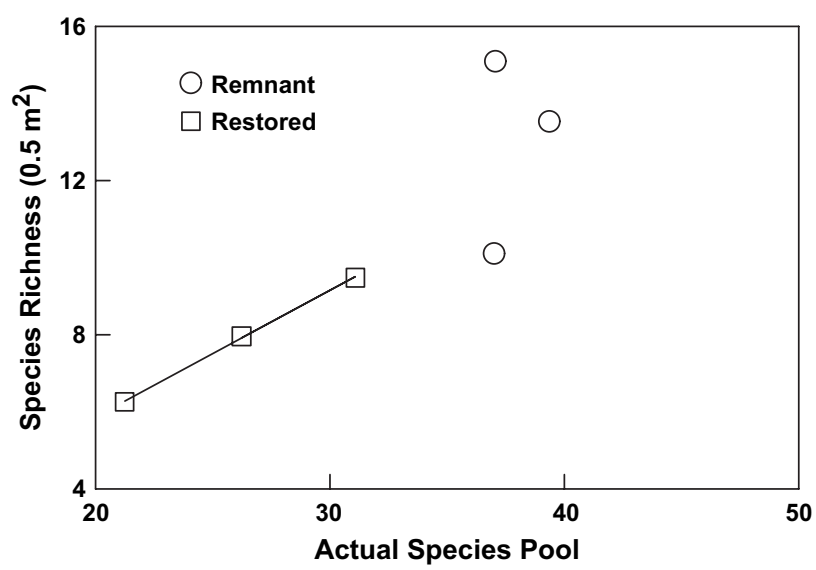

Figure 2. Relationship between the mean species richness of $0.5-\mathrm{m}^{2}$ plots and size of the actual species pool in remnant and restored tallgrass prairies in the Blackland Prairie region of central Texas,

U.S.A. Data from 12 plots per prairie were randomly partitioned into subsets from which mean richness of plots $(n=3)$ and size of the species pool $(n=9)$ were estimated. Averages of 1,000 of these estimates for each prairie then were plotted. The line is a linear regression fit to data from restored prairies $(r=0.999, p=0.02, n=3)$.

different results depending on assumptions. Exponents of power functions fit to relationships between species $S$ and number of functional groups were significantly greater in plot-scale communities assembled with replacement from the actual species pool of prairies than was observed. For a given species richness, $0.5-\mathrm{m}^{2}$ plots in both remnant and restored prairies contained fewer functional groups (more species per functional group) than expected at random (Fig. 4), evidence that functionally related species occurred together more frequently than expected by chance in both prairie types.

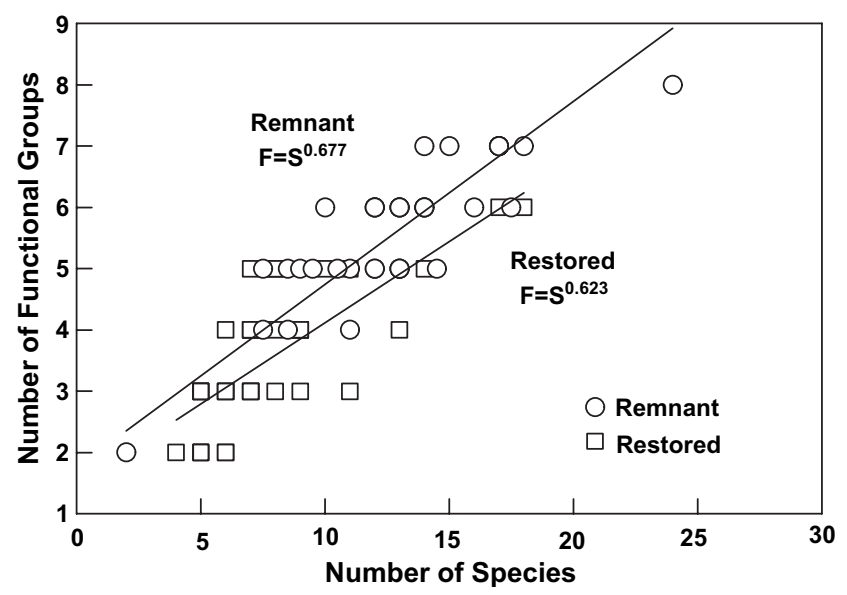

Figure 3. Relationships between the number of functional groups of plants ( $F$, defined based on growth form and phenology) and the number of plant species $(S)$ in $0.5-\mathrm{m}^{2}$ plots from remnant and restored tallgrass prairies across three sites in the Blackland Prairie region of Texas, U.S.A. $(n=36, p<0.0001)$. Number of observations per point varies between one and four. Lines were fit with power functions. 


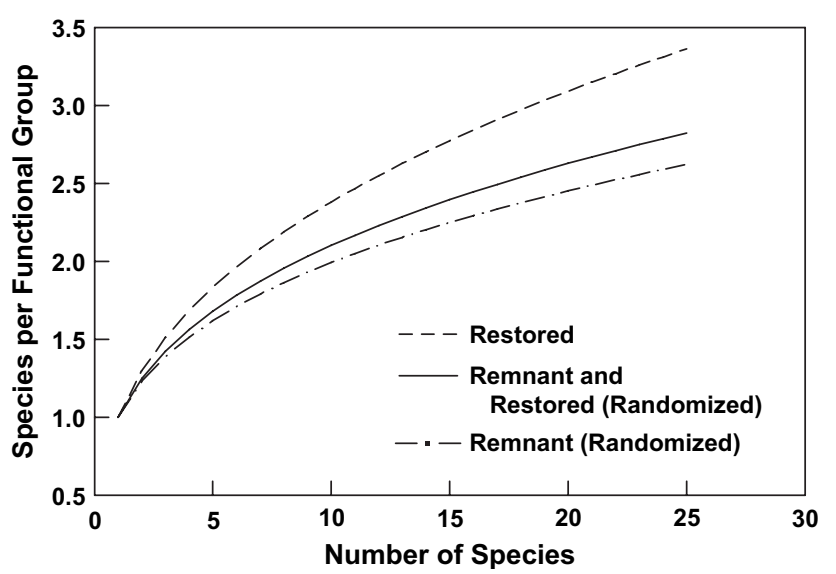

Figure 4. Observed relationships and Monte Carlo simulations (randomizations) of relationships between the number of plant species per functional group and the number of species in $0.5-\mathrm{m}^{2}$ plots from remnant and restored tallgrass prairies across three sites in central Texas, U.S.A. Lines were derived from power function fits to observed relationships between functional group richness and species number ( $n=36$, Fig. 3). Lines for randomizations were derived by fitting power functions to relationships between the number of functional groups and number of species in plots for which species composition was generated by randomly sampling with replacement from the larger species pool in which plots were embedded $(n=100$ randomizations for 12 plots each in each of the three remnant and restored prairies).

In contrast, scaling exponents observed for $0.5-\mathrm{m}^{2}$ plots in both remnant (0.677) and restored prairies $(0.623)$ fell within the $95 \%$ confidence intervals of exponents derived from randomizations that preserved abundances of various species (0.673-0.678 for remnants and $0.620-0.625$ for restored prairies). Given species abundances, observed communities did not differ from those expected by chance.

\section{Discussion}

\section{General Patterns}

Plant species diversity was greater in remnant than in restored Blackland prairies at all spatial scales studied. At the scale of entire prairies, both species richness and species evenness were greater in remnants. At the local or plot scale, remnants were more diverse because of greater richness alone. Only in restored grasslands was there evidence that plot-scale richness correlated with size of the species pool, implying that $\alpha$ richness in remnants was influenced more by limits on colonization or by other local ecological processes than by the number of species available for colonization.

Plots in remnant prairies contained more functional groups of species and fewer species per functional group on average than did plots in restored grasslands, evidence that resource partitioning or diversity of ecological function also was greater in remnants. Evenness was greater among dominant species and functional groups of species in remnant than in restored prairies, further indicating that resource partitioning may have contributed to the greater diversity in remnant prairies. Diversity patterns were surprisingly consistent across the three sites studied (three pairs of remnant and restored prairies), despite site-to-site differences in the sizes of prairies, specifics of management, and identity of the individuals or groups of people involved in restorations.

\section{Prairie Scale}

Species evenness was greater in remnant than in restored prairies apparently because plot-to-plot variation in species composition (as indicated by values of $\beta$ richness) also was greater in remnants at two of three sites. By reducing dominance, spatial variation in species composition should contribute to greater evenness. Spatial variation in species composition has been shown to increase during old-field succession (Inouye et al. 1987) and with time since grassland restoration (Sluis 2002), but evenness is not always greater in remnant than in restored grasslands (Kindscher \& Tieszen 1998). Plot-to-plot differences in composition could result from spatial heterogeneity in resources or in disturbance regimes but may also result from dispersal or recruitment limitations (Tilman 1994). The prairies that we studied were managed similarly (haying or burning) and domestic livestock were excluded, suggesting that differences between prairie types were related more to dispersal limitations than to heterogeneity in disturbance regimes.

Richness usually is greater in remnant than in restored prairies (Kindscher \& Tieszen 1998; Sluis 2002) likely in part because some of the species present in remnants are not included in seed mixtures dispersed during restoration. It is not obvious, however, that the addition of seeds alone will suffice to restore $S$ to the level of remnant prairies (i.e., Wilsey \& Polley 2003). Remnants contained more species at the plot scale and exhibited greater plotto-plot variation in $S$. The latter trend of greater $\beta$ diversity in remnants may result from dispersal or recruitment limitations (Tilman 1994) that are not well replicated during restoration. The former trend of greater $\alpha$ richness in remnants implies that processes that operate at the scale of interacting plants contribute to the greater overall $S$ of remnant prairies.

\section{Local Scale}

Local or plot-scale $S$ depends both on the number of potential colonizers (species pool) and on the rates of colonization and local extinction (Eriksson 1993). For local richness to be controlled mainly by size of the species pool, colonization and extinction rates must vary little among prairies. Ecological factors that cause colonization and mortality rates to vary will uncouple local richness from the species pool. Dispersal limitation is one such factor (Tilman 1994). By reducing the number of species that arrive at local sites, constraints on dispersal decrease the 
number of colonizers and increase site-to-site differences in species composition and richness.

Only for restored prairies was there a significant relationship between richness of $0.5-\mathrm{m}^{2}$ plots and pool size, as required by the "species pool hypothesis" (Taylor et al. 1990; Eriksson 1993). Weiher's (1999) data from herbaceous marshes failed to support the species pool hypothesis, but studies in other systems, including tallgrass prairie in Kansas, U.S.A. (Collins et al. 2002), have shown a positive correlation between species richness at local and larger scales (Pärtel et al. 1996). Here, the species pool was defined for each prairie as the number of species encountered during sampling. Because limits on dispersal were minimized for the pool of species seeded during restoration, differences in colonization and mortality rates among restored prairies probably also were minimized. The result would be a positive correlation between local richness and size of the species pool, as was observed. Effective dispersal also should minimize variation in extinction rates by contributing to the nearly ubiquitous presence of dominant species. Possibly because most natural limits on dispersal were overcome with seeding during restoration, most plots in restored prairies were dominated by a single $\mathrm{C}_{4}$ grass. Alternatively, $\mathrm{C}_{4}$ grasses simply may establish more consistently on bare soil than in vegetated remnant prairies.

Richness and evenness of functional groups of species and the number of functional groups represented among dominant species were greater at the plot scale in remnant prairies. Ecological function should differ more predictably between functional groups than between species, so greater functional group richness should be associated with greater diversity of ecological function and with fuller exploitation of resources. The differing slopes of species functional group relationships also indicated that co-occurring species were more ecologically diverse in remnant than in restored prairies. Wilson et al. (1996) found that species evenness increased with time following the establishment of grassland and attributed the increase in evenness to greater niche diversification. Two patterns in remnants, greater functional diversity among species and the absence of a correlation between $S$ of plots and the size of the species pool, are consistent with the interpretation that plot-scale $S$ is influenced more by local ecological processes in remnant than in restored prairies.

In both prairie types, plots contained more species per functional group than expected at random. That ecologically similar species are more aggregated in space than expected usually is interpreted to mean that competition or other local interactions had little effect on species composition. The pattern usually is attributed to poor mixing of the species pool (dispersal limitations) or to the shared habitat requirements of ecologically similar species (Webb 2000; Enquist et al. 2002). For neither prairie type did the distribution of species among functional groups differ from expectation when patterns of species abundances were preserved. Species abundances are determined by competition, dispersal, and other ecological factors. Because our initial randomization model did not discriminate among species, it failed to account for ecological processes that determine abundances. Rather than indicating that biotic factors played little role in determining the plot composition, our finding that species composition of plots differed from that predicted by a purely random model is consistent with an effect of ecological factors on local richness in both prairie types.

\section{Implications for Restoration}

By many measures, the restorations of Blackland prairie that we studied were highly successful. Dominant $\mathrm{C}_{4}$ grasses were restored by applying seed hay from remnant prairies to cultivated fields, species richness in restorations exceeded $50 \%$ of the level found in remnant prairies, exotic species were few, and biomass in restored prairies approximated that in remnants. Many of the functional properties of tallgrass prairie probably also had been restored. Indeed, Baer et al. (2002) found that establishment of dominant grasses sufficed to restore productivity and soil processes to levels approaching those measured in remnant tallgrass prairie. Yet, species diversity in restored prairies was on average only about one-third of that in remnants. Our current inability to re-create the patterns of plant species diversity found in remnant prairies challenges our understanding of community assemblage and emphasizes the urgency of protecting remnant prairies. Although not designed to directly test controls on diversity, our study suggests that local ecological processes, including resource partitioning and recruitment or dispersal dynamics, contribute to the greater diversity of remnant than restored Blackland prairies. To more completely or quickly restore species diversity thus may require practices and techniques that limit the distribution or abundances of dominant species (like grazing by ungulates; e.g., Howe 1994; Copeland et al. 2002), increase the number of species included in seed mixtures, and increase the proximity of plants of different functional groups (perhaps by ensuring greater uniformity of seed mixtures).

\section{Acknowledgments}

We are indebted to Bob and Mickey Burleson and to Paul and Virginia Mezynski for permitting us to sample their prairies. Katherine Jones, Kyle Tiner, Chris Kolodziejczyk, and Brett Boeselt assisted with fieldwork and separated plant material by species. David Chalcraft, Karen Hickman, and Matt Sanderson provided helpful reviews of the manuscript.

\section{LITERATURE CITED}

Baer, S. G., D. J. Kitchen, J. M. Blair, and C. W. Rice. 2002. Changes in ecosystem structure and function along a chronosequence of restored grasslands. Ecological Applications 12:1688-1701.

Chesson, P. 2000. Mechanisms of maintenance of species diversity. Annual Review of Ecology and Systematics 31:343-366. 
Collins, S. L., S. M. Glenn, and J. M. Briggs. 2002. Effect of local and regional processes on plant species richness in tallgrass prairie. Oikos 99:571-579.

Copeland, T. E., W. Sluis, and H. F. Howe. 2002. Fire season and dominance in an Illinois tallgrass prairie restoration. Restoration Ecology 10:315-323.

Cornell, H. V., and J. H. Lawton. 1992. Species interactions, local and regional processes, and limits to the richness of ecological communities: a theoretical perspective. Journal of Animal Ecology 61:1-12.

Duncan, R. P., and J. R. Young. 2000. Determinants of plant extinction and rarity 145 years after European settlement of Auckland, New Zealand. Ecology 81:3048-3061.

Enquist, B. J., J. P. Haskell, and B. H. Tiffney. 2002. General patterns of taxonomic and biomass partitioning in extant and fossil plant communities. Nature 419:610-613.

Eriksson, O. 1993. The species-pool hypothesis and plant community diversity. Oikos 68:371-374.

Gough, L., J. B. Grace, and K. L. Taylor. 1994. The relationship between species richness and community biomass: the importance of environmental variables. Oikos 70:271-279.

Howe, H. F. 1994. Managing species diversity in tallgrass prairie: assumptions and implications. Conservation Biology 8:691-704.

Huston, M. A. 1999. Local processes and regional patterns: appropriate scales for understanding variation in the diversity of plants and animals. Oikos 86:393-401.

Inouye, R. S., N. J. Huntly, D. Tilman, J. R. Tester, M. Stillwell, and K. C. Zinnel. 1987. Old-field succession on a Minnesota sand plain. Ecology 68:12-26.

Kindscher, K., and L. L. Tieszen. 1998. Floristic and soil organic matter changes after five and thirty-five years of native tallgrass prairie restoration. Restoration Ecology 6:181-196.

Lande, R. 1996. Statistics and partitioning of species diversity, and similarity among multiple communities. Oikos 76:5-13.

Loreau, M. 2000. Are communities saturated? On the relationship between $\alpha, \beta$ and $\gamma$ diversity. Ecology Letters 3:73-76.

Pärtel, M., M. Zobel, K. Zobel, and E. van der Maarel. 1996. The species pool and its relation to species richness: evidence from Estonian plant communities. Oikos 75:111-117.

Samson, F., and F. Knopf. 1994. Prairie conservation in North America. BioScience 44:418-421.
Sluis, W. J. 2002. Patterns of species richness and composition in recreated grassland. Restoration Ecology 10:677-684.

Smith, B., and J. B. Wilson. 1996. A consumer's guide to evenness indices. Oikos 76:70-82.

Srivastava, D. S. 1999. Using local-regional richness plots to test for species saturation: pitfalls and potentials. Journal of Animal Ecology 68:1-16.

Stirling, G., and B. Wilsey. 2001. Empirical relationships between species richness, evenness, and proportional diversity. American Naturalist 158:286-299.

Taylor, D. R., L. W. Aarssen, and C. Loehle. 1990. On the relationship between $\mathrm{r} / \mathrm{K}$ selection and environmental carrying capacity: a new habitat templet for plant life history strategies. Oikos 58:239-250.

Tilman, D. 1994. Competition and biodiversity in spatially structured habitats. Ecology 75:2-16.

Veech, J. A., K. S. Summerville, T. O. Crist, and J. C. Gering. 2002. The additive partitioning of species diversity: recent revival of an old idea. Oikos 99:3-9.

Webb, C. O. 2000. Exploring the phylogenetic structure of ecological communities: an example for rain forest trees. American Naturalist 156:145-155.

Weiher, E. 1999. The combined effects of scale and productivity on species richness. Journal of Ecology 87:1005-1011.

Wilsey, B. J., and H. W. Polley. 2003. Effects of seed additions and grazing history on diversity and productivity of subhumid grasslands. Ecology 84:920-931.

Wilsey, B. J., and H. W. Polley. 2004. Realistically low species evenness does not alter grassland species richness-productivity relationships. Ecology 85:2693-2700.

Wilson, J. B., J. B. Steel, W. M. King, and H. Gitay. 1999. The effect of spatial scale on evenness. Journal of Vegetation Science 10: 463-468.

Wilson, J. B., T. C. E. Wells, I. C. Trueman, G. Jones, M. D. Atkinson, J. J. Crawley, M. E. Dodd, and J. Silvertown. 1996. Are there assembly rules for plant species abundance? An investigation in relation to soil resources and successional trends. Journal of Ecology 84: $527-538$.

Zobel, M. 1997. The relative role of species pools in determining plant species richness: an alternative explanation of species coexistence? Trends in Ecology and Evolution 12:266-269. 